\title{
La écfrasis de la tienda del rey Adrastro, en el Roman de Thèbes: estructura, estrategias retóricas e intertextualidad
}

\author{
Gerardo Altamirano MEZA \\ Universidad Nacional Autónoma de México
}

\begin{abstract}
Uno de los motivos ecfrásticos más frecuentes en la literatura medieval es el de la tienda historiada. Es decir, la descripción de elementos figurativos, dibujados o bordados que se hallan en los paños de una tienda militar, generalmente de carácter regio. En este escrito se analiza la descripción o écfrasis de la tienda de Adrastro que aparece en el Roman de Thèbes y que, presumiblemente, es el arquetipo de otras descripciones medievales, como la tienda de Alejandro, que se describe en el Libro de Alexandre, y la tienda de Don Amor, descrita en el Libro de Buen Amor. A lo largo del ensayo se evidencia la manera en la que el autor estructura el pasaje, algunas estrategias retóricas (como la enumeratio, la aposiopesis y la hipérbole) y, asimismo, se realiza un diálogo hipertextual, tanto con otras obras medievales como con las fuentes clásicas.
\end{abstract}

Palabras ClaVE: écfrasis, Roman de Thèbes, Adrastro, descriptio, matière antique, tienda militar.

One of the most common ekphrastic motives in medieval literature is the historiated tent. In other words, the figurative elements described, whether drawn or embroidered, which can be found on the fabrics of a military tent, usually of royal nature. On this paper, the author analyses the ekphrasis of Adrastrus' tent, which is part of the narrative poem known as Roman de Thèbes and which, presumably, is the archetype of other medieval descriptions, such as the Alexander's tent, which appears in the Libro de Alexandre and Don Amor's tent, which appears in the Libro de Buen Amor. This essay analyseshow the author structures the passage and how some rethorical strategies (such as the enumeratio, the aposiopesis and the hyperbole) are used. In the same manner, it tries to suggest an hypertextual dialogue with other medieval works and some classical sources.

KeY worDS: ekphrasis, Roman de Thèbes, Adrastus, descriptio, matière antique, military tent.

En las últimas décadas, la écfrasis — entendida como la representación verbal de una representación visual (Heffernan, 1993: 222) — ha sido objeto de múltiples estudios que, no obstante, suelen olvidar que, entre las literaturas clásica y la moderna, la literatura medieval también incluyó descripciones vívidas de objetos suntuosos y 
estéticos. ${ }^{1}$ En efecto, aunque los autores medievales utilizaron el término descriptio y raramente hicieron uso del vocablo griego ${ }^{2}$ - pues la Edad Media tuvo como lengua franca el latín-, estos escritores también cultivaron dicha técnica literaria, misma que permitió que, para entonces, en las nacientes literaturas modernas se describiera objetos como escudos, pinturas murales y tiendas militares, en cuyos paños, a manera de lienzos, supuestamente se plasmaron elementos figurativos que llevaban al lector o auditor a los terrenos de lo admirable o lo maravilloso. ${ }^{3}$ Es precisamente el motivo de la descripción de la tienda historiada uno de los más frecuentes en la literatura medieval. Encontramos, de esta suerte, descripciones de tiendas en textos como: el Roman d'Eneas (11.7348-7416), escrito hacia 1155; el Roman d'Alexandre(I, 11.1948-2069), redactado hacia 1180; el Libro de Alexandre (cc. 2540-2595), cuya composición data hacia 1270, y finalmente, el Libro de Buen Amor (cc. 1265-1301), que Juan Ruiz escribió entre 1330 y 1340 . No obstante, de manera directa o indirecta, todas estas variantes de lo que podemos denominar justamente un motivo ecfrástico tienen su origen en la descripción de la tienda del rey Adrastro, que aparece en el anónimo Roman de Thèbes. ${ }^{4}$ En este escrito tengo como objetivos evidenciar la estructura de la composición descriptiva, aclarar algunas funciones literarias y estrategias retóricas que el pasaje conlleva, así como, finalmente, entablar un diálogo intertextual entre este ejemplo de écfrasis medieval y algunos de sus hipotextos e hipertextos. Para lograrlo, en la primera

\footnotetext{
${ }^{1}$ El concepto de écfrasis ha sido ampliamente debatido. De esta suerte, partiendo de una de las definiciones modernas más canónicas —aquella que señala que la écfrasis es "the poetic description of a pictorical or sculptural work of art" (Spitzer, "Ode on a Grecian Urn...", 203) -, Pineda ha señalado que "esta definición, que ha sido - y sigue siendo - objeto de continuas matizaciones [...] cuenta con apenas cincuenta años, mientras que el término que la aloja goza de una tradición de siglos" ("La invención de la écfrasis", 252). En efecto, el término de écfrasis se remonta milenariamente a la reflexión literaria que hicieron, tan sólo por mencionar algunos, autores como: Hermógenes, Aftonio y Theon de Alejandría, quienes en sus manuales de retórica, llamados progymnasmata, incluían la descripción como uno de los métodos discursivos más importantes. Sobre la tradición del término, ver el artículo de Pimentel "Ecfrasis: la representación verbal de un objeto".

${ }^{2}$ La palabra écfrasis proviene de los étimos griegos $\check{\kappa} \kappa=$ afuera; y $\varphi \rho \alpha \sigma l \zeta=$ declarar, pronunciar, decir.

${ }^{3}$ Por maravilloso entiendo una categoría cultural (representada en aspectos literarios, legendarios y estéticos) que descansa en la extraordinariedad de un objeto, territorio, entidad, etcétera, y que resulta más o menos común en las literaturas medievales. Lo maravilloso en literatura medieval ha sido ya ampliamente estudiado por autores como Le Goff en su paradigmático escrito Lo maravilloso en el Occidente medieval. Cabría recordar aquí que el vocablo deriva del sustantivo plural neutro latino mirabilia, mismo que tiene como raíz el verbo latino miror-mirari, que originalmente implicó el acto de observar algo y hacerlo con asombro. Por otra parte, este vocablo también se formó gracias al sufijo abilis que indicaba una cualidad inherente al objeto. Mirar + abilis darían como resultado, por ende, el adjetivo mirabilis que, sustantivado de manera plural, creó la voz mirabilia, origen de los diversos vocablos que en lenguas romances son equiparables a nuestro sustantivo maravilla.

${ }^{4}$ A partir de aquí, abrevio el título de la obra como RT. Del mismo modo, las citas que hago dentro del texto, regularmente en idioma original, las obtengo de la edición de Guy Raynaud de Lage; mientras que, a nota al pie, ofrezco la traducción que hace P. Gracia, en su edición a El Libro de Tebas. Cabe mencionar, finalmente, como ya bien lo propusieron Faral (1913) y Lecoy (1938), que el motivo de la tienda historiada debe mucho a la literatura clásica. Sobre todo a la descripción que Ovidio hace con respecto a los palacios del Sol, en el Libro I de las Metamorfosis.
} 
parte de este escrito me enfocaré en las generalidades de la obra y de la descripción; señalaré cuáles son algunas de las estrategias retóricas utilizadas y, asimismo, expondré algunas relaciones intertextuales que esta écfrasis conlleva con otros escritos; en la segunda parte se ofrece un anexo que incluye la transcripción y la traducción del pasaje aquí estudiado.

\section{Generalidades de la obra y del pasaje. Estructura, estrategias retóricas e intertextualidad}

El $R T$ es el texto más arcaico de la triada de romans de matière antique. ${ }^{5}$ Su datación se ha calculado hacia 1150 . Se trata de una obra de diez mil quinientos sesenta y dos versos, escrita en francés antiguo que reactualiza, para el siglo XII, la historia de Edipo: la unión con su madre, el fatum inexorable que lo abruma, la maldición que pesa sobre sus hijos y la guerra que éstos emprenden entre sí. En la actualidad se conservan seis manuscritos. ${ }^{6}$ Asimismo, hasta hoy existen seis ediciones modernas en lengua original, entre las que destacan la de Pheleps Ripley y la de Léopold Constants, por ser las primeras ediciones críticas del texto; y la de Aimé Petit, por ser la más reciente. ${ }^{7} \mathrm{Al}$ igual que su hipotexto - la Tebaida de Estacio-, esta obra se centra en la lucha fratricida entre Etéocles y Polínices quienes, después de la muerte de su padre y hermano a la vez - Edipo - , deciden hacer un pacto para turnarse de manera anual el gobierno de la ciudad de Tebas.

Como en la historia clásica se cuenta, al permanecer Etéocles como gobernante de la ciudad, Polínices tiene que buscar suerte propia en reinos más o menos cercanos. Es así que llega hasta Argos, donde conoce a Tideo — príncipe desterrado de Calidón—, así como al gobernante de la ciudad argiva, Adrasto. Después del año acordado, Etéo-

\footnotetext{
${ }^{5}$ Con este nombre se conoce a un grupo de textos que, en la segunda mitad del siglo XII, se redactaron en la zona anglonormanda y en lengua vernácula. Éstos pueden considerarse traducciones de ciertas obras clásicas, entendiendo que la traducción o translatio, en la Edad Media, no sólo implica la mudanza de una lengua $a$ a una lengua $b$, sino también un proceso de readaptación al contexto cultural receptor. Esta triada clásica se compone por: el Roman de Thèbes, el Roman d'Eneas y el Roman de Troie, que, para su época, reactualizaron historias de Homero, Virgilio y Estacio.

${ }^{6}$ La signaturas en las distintas bibliotecas es como sigue: 1) Angers, Bibliothèque municipale, Ms. 26; 2) Cologny (Genova), Fondation Martin Bodmer, Ms. 18, f. 185-268; 3) Londres, British Library, Ms. 34114, f. 164-226; 4) París, Bibliothèque Nationale de France, Ms. 60, f. 1-41; 5) París, Bibliothèque Nationale de France, Ms. 375, f. 36-67; 6) París, Bibliothèque Nationale de France, Ms. 784, f. 1-67.

${ }^{7}$ Cronológicamente las ediciones del $R T$ son las siguientes: a) Le Roman de Thèbes. Ed. Léopold Constans. 2 tt. París: Firmin Didot pour la Société des Anciens Textes français, 1890; b) Dana Phelps Ripley, A Critical Edition of the "Roman de Thebes" (Lines 1-5394). North Carolina: University of North CarolinaChapel Hill, 1960; c) G. Raynaud, "Les fragments d'Angers du Roman de Thèbes", Romania, 90, 1969, pp. 402-409; d) Le Roman de Thèbes. Ed. Guy Raynaud de Lage. París: Champion, 1966; e) Le Roman de Thèbes. Édition du manuscrit S (Londres, Brit. Libr., Add. 3|4114). Trad. Francine Mora-Lebrun. París: Librairie Générale Française, 1995. (Livre de poche, 4536. Lettres gothiques); f) Le Roman de Thèbes. Ed. bilingüe. Trad. Aimé Petit. París: Champion, 2008 (Champion Classiques. Moyen Âge, 25).
} 
cles, apoyado por los varones que una vez le juraron vasallaje, se niega a entregar la regencia de Tebas a su hermano, por lo que éste - con ayuda de Tideo y Adrasto, de quienes se convierte, respectivamente, en yerno y concuño- decide invadir su propia patria para hacer cumplir la promesa que, empero, llevará a los protagonistas al fratricidio que, bajo la óptica medieval, es el resultado punitivo para los hermanos, engendrados bajo el pecado del incesto. ${ }^{8}$

El autor del Roman, anónimo para nosotros, conserva la mayoría de los pasajes y personajes que narra y describe Estacio. No obstante, introduce el texto con una síntesis del mito de Edipo, cuya historia en la Edad Media fue tan popular que su difusión inspiró el nacimiento de las leyendas hagiográficas de san Julián el hospitalario y san Albano, así como la del papa Gregorio I. Además de esto, como es usual en este tipo de obras y como queda aludido con anterioridad, la historia se adapta al contexto y a los valores del Medioevo, entre los que se encuentran el universo caballeresco y el del amor cortés, así como la explicación cristiana del mundo. Del mismo modo, las técnicas retóricas y los motivos que utiliza el autor muchas veces son aquellos propios de literatura medieval. En este sentido, cabría mencionar no sólo el exordium de la obra, ya estudiado por críticos como Faral (1913: 420 y ss.), sino también las descriptiones ecfrásticas de ciertos objetos de lujo que contiene el texto: por una parte, la écfrasis del carro de Anfirao (11.4950-5016), a quien el autor de la obra presenta como un arzobispo cristiano; ${ }^{9}$ mientras que, por otro lado, también se halla la descripción de la tienda del rey Adrastro.

Una de las características que distingue la descripción de la tienda del rey Adrasto de otras écfrasis de este tipo, en literaturas medievales, es que esta descriptio se presenta doble o dividida en dos pasajes intradiegéticamente distintos. ${ }^{10} \mathrm{El}$ primero de ellos abarca cuarenta y un versos (11.3175-3216), es el más corto, y tiene como contexto la invasión del castillo de Montflor, en el páramo de Valflor, cuyos habitantes le deben vasallaje a Etéocles. Montflor es una poderosa fortaleza que impide el paso argivo hacia el camino que lleva a Tebas y ante cuyas puertas acampa el ejército de Argos. Justo

\footnotetext{
${ }^{8}$ Para el tema del incesto y del odio como motor de la narración en esta obra, véase el artículo de Desprès Caubrière, "La haine comme résonance du mythe dans le Roman de Thèbes".

${ }^{9}$ La écfrasis completa del carro es como sigue: "Quiero explicar cómo se comporta Anfirao en el combate. Anfirao va en un carro que había sido hecho más allá de las tierras de Santo Tomás. Vulcano meditó profundamente antes de hacerlo y le llevó largo tiempo construirlo. Después de mucho estudio y reflexión, representó la luna y el sol y fundió el firmamento por arte de encanto. Nueve esferas representó allí, ordenadamente; en la mayor figuró las estrellas, mientras que en las restantes, que eran menores, representó los planetas y su curso; colocó la novena en el centro del mundo, esto es, la tierra y el mar profundo. Sobre la tierra pintó hombres y bestias; en el mar, peces, vientos y tempestades. Quien tiene algún conocimiento de las Siete Artes puede aprender mucho aquí. En el otro costado están los gigantes, llenos de orgullo e insolencia, quieren desheredar a los dioses y expulsarlos de los cielos por la fuerza" (Libro de Tebas, 1997: 123).

${ }^{10}$ En la obra, el motivo de la representación doble, o por lo menos del número dos, se presenta con recurrencia. Así, dos son los protagonistas de la lucha fratricida, dos sus hermanas, dos las representaciones del pasaje de la esfinge y, como queda aquí asentado, dos las veces en las que se describe la tienda, una por el exterior y otra en el interior.
} 
antes de la invasión, se describe el exterior del pabellón del monarca. Esta primera descripción de la tienda puede dividirse, a su vez, en once puntos de representación que, curiosamente, parecerían alternar, la mayoría de las veces, entre la descripción de elementos naturales contrastados con elementos sociales, políticos e incluso tecnológicos; en suma, esta primera parte de la écfrasis se condensa en el binomio de la representación de naturaleza versus cultura.

En primer lugar, el autor menciona ciertas generalidades de la construcción. Por un lado, se afirma su localización, es decir, se utiliza una estrategia retórica llamada dispositio: la tienda se halla enfrente de una torre del castillo de Montflor. Asimismo, el autor menciona ciertos materiales y otras generalidades de la construcción efímera: se trata de una tienda hecha en sedas finas y multicolores. En segundo lugar, se afirma que ciertos estampados de la tela, de modo general, representan la flora y la fauna; y ésa es la primera mención de la representación del mundo natural, cuyo número total a lo largo de la écfrasis suma cinco. En tercer lugar, el autor afirma que, sobre los paños de la tienda, se hallan representados algunos aspectos que caracterizan a las sociedades humanas, como "les estoires, / les vielles gestes, les memoires / et les justises et les ples, / les jugemenz et les forfés" (11.3179-3182), ${ }^{11}$ es decir, una serie de aspectos que podemos englobar en el tema de la representación del mundo histórico y político.

En el siguiente punto, el autor contrapone esos aspectos sociales a la segunda representación del mundo natural, al afirmar que, en las telas de la tienda, hay también figuras que evocan valles y montañas. Después, como quinto elemento, haciendo uso de un catálogo o enumeración, el autor evoca el mundo cortesano, al mencionar que ciertas figuras ahí plasmadas representan el mundo social, específicamente: "les quaroles et li bal, / les puceles et leur ami / et les dames et leur mari" (11.3184-86). ${ }^{12}$ En una sexta categoría, el autor contrapone estas últimas representaciones a la de los elementos agua y tierra, pues afirma que también hay ahí figuras que evocan mares y ríos; mientras que, en un nuevo recuento de aspectos naturales, el clérigo afirma la presencia de distintos tipos de bestias, entre los que se encuentran aves y caballos. ${ }^{13}$ Después, como octavo elemento, a modo también de filigrana ecfrástica, se enfoca en la multiplicidad de ciertas características físicas de los hombres ahí figurados, pues sobre la tienda se

${ }^{11}$ De aquí en adelante, todas las citas al texto en idioma original serán extraídas de la edición de Guy Raynaud, mientras que, en nota a pie, pondré la traducción que propone Paloma Gracia en el texto publicado por la editorial Gredos, El libro de Tebas, y que se encuentra prosificado, por esta razón indicaré aquí la página y arriba los versos o las laisses o tiradas correspondientes. En este caso, la traducción dice lo siguiente: "las historias, las gestas antiguas, las memorias, los castigos, los procesos, los juicios y los delitos" (89-90).

12 "Las danzas y los bailes, las doncellas y sus amigos, las damas y sus maridos" (90).

${ }^{13}$ En la tradición ecfrástica es pertinente hablar de la transmisión del escudo historiado que, evidentemente, tiene su punto de partida en la descripción del escudo de Aquiles que hace Homero, en la Ilíada (XVIII). Este objeto y esta descripción, cabe recordar, fueron transmitidas a la Edad Media, por medio de ciertos opúsculos, como la Ilias Latina, en el que se describe ciertos grabados en el escudo de Aquiles, mismos que pueden relacionarse con los aspectos aquí tratados, como sigue: "Terra gerit silvas horrendaque monstra ferarum/ fluminaque et montes cumque altis oppida muris” (Ilias Latina, XVII, VV. 876-877). 


\section{$20 \square$ LA ÉCFRASIS DE LA TIENDA DEL REY ADRASTRO, EN EL ROMAN DE THÈBES}

ven los rostros de: "les vielz houmes et les chanus / et les chauz et les cheveluz" (11.3191-3192). ${ }^{14}$

Casi para finalizar, afirma el autor la representación del bosque y después, de nueva cuenta como contraposición del binomio naturaleza/cultura, enumera distintos elementos relacionados al mundo de la guerra (real o ficticia), como "les embuchemenz, les aguez, / les cembiaux et les envaïes / que danzel font por lor amis" (11.3194-3196). ${ }^{15}$ Asimismo, en este punto, se dice que en los paños de la tienda del rey Adrasto se hallan representadas ciertas construcciones arquitectónicas, como "les chastiaux et les citez, / les forteresces, les fertez" (11.3197-3198). ${ }^{16}$

Finalmente, la parte más extensa de esta primera écfrasis de la tienda del rey la ocupa la descripción de un águila autómata (11.3199-3212), elaborada en metales y piedras preciosas que corona el exterior y el punto más alto de la tienda y cuya maravilla técnica radica en convertir la luz solar en fuego defensivo que, de requerirlo, se utiliza en contra del enemigo. Estos once puntos se desglosan en el siguiente esquema:

1. Generalidades de la construcción (11.3175-3178).

1.1. Localización de la tienda en el páramo de Valflor (11.3175-3176).

1.2. Material de construcción (1.3177).

2. El mundo natural 1: la flora y la fauna (1.3178).

3. El mundo histórico-político (11.3179-3182).

3.1. Viejas gestas y memorias (11.3179-3180).

3.2. Castigos y procesos (11.3181).

3.3. Juicios y delitos (11.3182).

4. El mundo natural 2: la naturaleza del terreno (1.3183).

5. El mundo social (11.3184-86).

5.1. Las danzas y los bailes (1.3184).

5.2. Las doncellas y sus amigos (1.3185).

5.3. Las damas y sus maridos (1.3186).

6. El mundo natural 3: los prados y los ríos (1.3187).

7. El mundo natural 4: el mundo animal (11.3188-3190).

7.1. La multiplicidad de las bestias (1.3188).

7.2. Aves: azores y los gavilanes (1.3189).

7.3. Caballos: rocines y los destreros (1.3190).

8. La multiplicidad de las fisonomías humanas (1.3191-3192).

8.1. Los viejos y los jóvenes (1.3191).

8.2. Los calvos y los peludos (1.3192).

9. El mundo natural 5: los bosques y las florestas (1.3193).

\footnotetext{
14 "Los ancianos y los canosos, los calvos y los cabelludos" (90).

15 "Las emboscadas, los ardides, las justas y las contiendas que los donceles libran por sus amigas" (90).

16 "Los castilllos y las cuidades, y las fortalezas, las plazas fuertes" (90).
} 
10. El mundo de la guerra (11.3194-3198).

10.1. Las emboscadas y los ardides (1.3194).

10.2. Las justas y las contiendas (1.3195-3196).

10.3. Los castillos y las ciudades (1.3197).

10.4. Las fortalezas y las plazas (1.3198).

11. El águila autómata (11.3199-3212).

La segunda parte de la descripción de la tienda del rey Adrasto se realiza casi mil versos después de la primera écfrasis y abarca prácticamente el doble de laisses o tiradas que su precedente (11.4217-4306, ochenta y nueve versos en total). El contexto en el que se ofrece esta segunda descripción del mismo objeto es totalmente distinto, pues, para el v.4217, Polínices y sus aliados han derrotado ya a los habitantes del castillo de Montflor y han llegado casi hasta las puertas de Tebas, a la que pretenden asediar. Dentro de esta ciudad, Etéocles, casi obligado por la nobleza tebana, acepta que el gobierno se vuelva un coprincipado entre ambos hermanos, con la condición de ser él el único que ostente el título nobiliario. Los hombres de Etéocles y su propia madre aplauden esta decisión y buscan a alguien que quiera ir como mensajero al campamento de los argivos, para comunicar esto a Polínices. Nadie desea realizar tal expedición, pues temen una venganza por parte de los caballeros de Tideo, quien, versos atrás, hubo realizado la tarea de mensajero en Tebas y fuera casi muerto por los hombres de Etéocles.

Así pues, al no encontrar ningún voluntario varón para llevar el mensaje del gobernante, la reina Yocasta ofrece ir, junto con sus hijas - las princesas Antígona e Ismene-, hasta el campamento del enemigo y hablar con su otro vástago. A la mañana siguiente, las damas son acompañadas por tres varones de alta alcurnia, hasta un punto neutro entre los dos bandos y ahí se encuentran con Partenopeo, hijo de la famosa amazona Atalanta, quien apoya al ejército de los argivos y quien también, al ver a Antígona, se prenda de amor por ella. Partenopeo es, desde este punto, quien escolta a la comitiva de mensajeros y el grupo se interna en el campamento de los argivos: "Más de sesenta mil griegos salen de las tiendas para verlas; quieren escoger a la más bella pero no aciertan a conseguirlo, pues su belleza no tiene medida" (Libro de Tebas, 1997: 109), se señala en el texto. Finalmente, Partenopeo las conduce directamente hacia la tienda del rey Adrasto y, antes de que el narrador comience a relatar la plática entre los dos bandos, pausa un momento la acción — logrando con ello una aposiopesis $-{ }^{17}$ para referirse al pabellón del rey, que se describe bajo once puntos principales:

\footnotetext{
${ }^{17}$ El DRAE define esta figura del modo siguiente: "acto de dejar incompleta una frase o no acabar de aclarar una especie, dando, sin embargo, a entender el sentido de lo que no se dice, y a veces más de lo que se calla" (DRAE, s.v Aposiopesis, las negritas son mías). Beristáin define la reticencia o aposiopesis como: "Figura de pensamiento que se realiza al omitir una expresión, lo que produce una ruptura en el discurso, que deja inacabada una frase que pierde, así parte de su sentido" (Beristáin, 1992: s.v. reticencia).
} 
1. Generalidades y materiales de la construcción (11.4217-4222).

2. Mapamundi (11.4223-4262).

3. Catálogo de piedras preciosas (11.4263-4268).

4. Calendario alegórico (11.4269-4276).

5. El mundo histórico (11.4277-4284).

6. Catálogo de animales (11.4285-4286).

7. Elementos de la alfombra (11.4287-4289).

8. Paloma de marfil (11.4290-4296).

9. Tapices del suelo (11.4297-4298).

10. Cuerdas de tensión (11.4299-4301).

11. Dimensiones (11.4302-4306).

Cada uno de esos puntos contiene ciertas especificidades y se vale de estrategias retóricas específicas, de las cuales cabría detallar algunos aspectos. En primer lugar, habría que recordar que, acerca de las generalidades y los materiales de construcción, el autor inaugura la écfrasis al afimar que: "Li trez est merveilleux et granz / et entailliez a fleurs par panz." (11.4217- 4218). ${ }^{18}$ Después devela que el material de construcción es seda púrpura de Alejandría y confiesa que "dedenz ot paint meinte merveille" $(1.4222),{ }^{19}$ frase que inaugura la descripción de los aspectos figurativos plasmados en la tienda.

En primer lugar se encuentra un mapamundi. Éste, cabe decir, es el bloque temático más extenso y detallado en la descripción. De él, primeramente, se afirma la técnica de hechura, sus características físicas y localización; se trata de una pieza "bien entailliee, bien roonde; / u pan devant desus l'entree, / a or batu, menu ouvree" (1.4224-4226). ${ }^{20}$ Posteriormente, se habla de cinco zonas en las que se divide esta representación del mundo, mas no se dice si la división es vertical u horizontal, sólo se afirma que los grabados son "si paintes com les fist Nature" (11.4228), ${ }^{21}$ es decir, que el ejercicio mimético (o mejor dicho, doblemente mimético, al ser una representación de una representación) obedece a las disposiciones de la Creación, curiosamente aquí aludida no por ninguna potestad cristiana, sino por Naturaleza. De este modo, se habla de dos zonas, las extremas, cubiertas de hielo y nieve; en medio de ellas, se encuentra una zona extremadamente cálida. Entre cada una de esas zonas extremas se afirma la existencia de una zona templada que es la única habitable; mientras que, como si se tratara de una representación de la imago mundi, tan característica de la tradición ecfrástica de escudos y tiendas de guerra, el autor afirma que esa representación del mundo se encuentra, también, franqueada por el Océano.

18 "La tienda era grande y maravillosa, con sus páneles bordados de flores" (109).

19 "En cuya superficie se habían pintado numerosas maravillas" (109).

20 "[un mapamundi] delicadamente bordado y completamente redondo se representaba en un panel recubierto de oro y trabajado a maravilla, sobre la puerta de la entrada" (109).

21 "[cinco zonas] pintadas tal como Naturaleza las había hecho" (109). 
Como he mencionado, de esas cinco partes, la zona habitable es la que mayormente se describe. Sobre esta zona, según el autor, el artífice plasmó ciudades, reinos, reyes, los cuatro ríos del Paraíso, los montes y mares más famosos, así como cada tierra con su nombre e incluso los setenta y dos lenguajes supuestamente existentes sobre la faz de lo habitable. ${ }^{22}$ Así, sobre los paños de ese edificio efímero:

Iluec sont les citez antives

o tours, o murset o eschives

D'or musique sont li torel,

et li portaill et li tournel, tuit li reaume, tuit li roi, et chascune terre par soi, et li septante et dui langaje et mer Betee et mer Sauvage. Rouge mer fu fete a neel, et le pas ausfilz Ysrael. De Paradis li quatre flun; Ethna y est, qui giete fun. $(11.4241-4252)^{23}$

Del mismo modo, el autor detalla que el anónimo artífice ha representado cierta variedad racial de los hombres tal como los ha hecho naturaleza, pues "li nostre home i sont bien peint, / Cil d'Ethÿoppe trestuit teint" (11.4255-4256). ${ }^{24}$ Después, como he mencionado, se afirma la existencia del Océano y, posterior a ella, el autor afirma que, sobre el oro que cubre o enmarca esta representación, se halla un número considerable de piedras preciosas. Para hacerlo, hace uso de un catálogo o enumeratio de estos elementos minerales que tiene, intradiegéticamente, una función, la de brindar claridad en el interior de este recinto, pues las piedras "contre soleill grant clarté donent" $(1.4268) .{ }^{25}$

Hacia el v. 4269, el autor inaugura el segundo elemento más extenso de la écfrasis de la tienda de Adrasto: la descripción del calendario alegórico. Cabe mencionar que,

${ }^{22}$ Resulta curioso pensar que el motivo de la representación del mapamundi, sea o no en una tienda historiada, se encuentra vigente incluso en la literatura moderna. Así, en su cuento, "La cámara de las estatuas", Jorge Luis Borges narra la historia de un rey malvado que decide abrir una serie de habitaciones prohibidas, en un legendario castillo. Muchos aspectos desconcertantes se presentan a sus ojos, tras esta violación. Entre ellas, no sólo la imagen de los árabes que invaden España, sino que, "en la cuarta encontraron un mapamundi, donde estaban los reinos, las ciudades, los mares, los castillos y los peligros, cada cual con su nombre verdadero y con su precisa figura" (Borges, 1995: 36).

23 "Allí estaban las ciudades antiguas con sus torres, sus murallas y sus defensas. Las torretas, los portales y los puentes levadizos eran de paño de oro; todos los reinos, todos los reyes, cada país según su forma y los setenta y dos lenguajes y el mar Blanco y el mar Salvaje. El mar Rojo estaba nielado, como el paso de los hijos de Israel. También estaban los cuatro ríos del Paraíso y el Etna que lanza humo" (109).

24 "Los hombres como nosotros estaban bien pintados, mientras que los de Etiopía eran completamente negros" (110).

25 "Daban una intensa claridad con el reflejo del sol" (110). 


\section{$24 \square$ LA ÉCFRASIS DE LA TIENDA DEL REY ADRASTRO, EN EL ROMAN DE THÈBES}

a diferencia de textos como el Alexandre o el Libro de Buen Amor, en el Roman de Thèbes no se hace una descripción de cada uno de los doce meses del año, sino que sólo se menciona que éstos están situados, con respecto al mapamundi: "De l'autre part, el destre pan" (1.4269), ${ }^{26}$ y esto lo logra el escritor haciendo uso de una dispositio. Sin embargo, lo que sí se detalla es la presencia tanto de Estío o Verano y la de Invierno, como se lee a continuación:

Estez y est o ses amours, o ses biautez et o ses flours. O cent coulors est painz Estez; Yver li fet granz tempestez, qui nege et pluet et vente et grelle, et ses ourez ensemble melle.

$$
(11.4271-4276)^{27}
$$

En efecto, tal como Ovidio describe ciertos personajes en la corte áurea, ${ }^{28}$ aquí también el autor del $R T$ hace acompañar a estas personificaciones de ciertas características que les son propias: Estío se adorna con cien colores y flores; mientras que Invierno se retrata con nieves, lluvia y tempestades que hacen zozobrar a la humanidad. Este modelo se seguirá utilizando en las descripciones posteriores de tiendas reales. Basta pensar cómo, de la tienda de Alejandro, en el Libro de Alexandre, se dice que, en uno de los paneles:

Sedié el mes de Mayo coronado de flores, afeitando los campos de diversas colores, organenando las mayas e cantando d'amores, espigando las mieses que siembran lavradores.

(Libro de Alejandro, c. 2559)

26 "En el lado opuesto, sobre el panel derecho" (110).

27 "Allí estaba el Estío con sus amores, sus encantos y flores; con cien colores estaba pintado Estío. Invierno provocaba grandes tempestades: nieve, lluvia, viento y granizo, y obligaba a soportar sus huracanes" (110).

${ }^{28}$ En sus Metamorfosis, Ovidio afirma que al momento de llegar Faetón ante, literalmente, el rey Sol, éste se encuentra rodeado de su corte fastuosa, compuesta por los Días, los Meses, los Siglos y las Horas, además de las estaciones del año. De este modo, en aquella obra se afirma que:

A dextra laevaque Dies et Mensis et Annus

Saeculaque et positae spatiis aequalibus Horae

Verque novum stabat cinctum florente corona,

stabat nuda Aestas et spicea serta gerebat,

stabat et Autumnuscalcatissordidusuvis

et glacialis Hiems canos hirsuta capillos (Metamorphoseon, II, vv. 25-30). 
Por su parte, Juan Ruiz, arcipreste de Hita, presenta un calendario alegórico en la tienda de Don Amor. En él, también los meses y las estaciones son representados con acciones que les son propias. Así, Abril se representa de la siguiente manera:

El terçero fidalgo está de flores lleno;

con los vientos que faze grana trigo e çenteno;

faze poner estacas que dan azeite bueno;

a los moços medrosos ya los espanta el trueno.

(Libro de Buen Amor, c. 1286)

Pero regresemos a la tienda del rey Adrastro. Casi para finalizar, el autor describe aspectos históricos y políticos relacionados con los argivos; se alude, entonces, a los ancestros del rey, a las leyes que promovieron y a sus gestas heroicas, gestas de reyes "ces qui sont digne de mémoire" (1.4283). ${ }^{29} \mathrm{~A}$ éstas, las circunda una cinta en la que se representan, por asociación a la bravura y a la dignidad real, una serie de bestias feroces: osos, leones y leopardos (1.4285-4286).

Por otro lado, el autor parece guiar la potencial mirada del lector en dirección vertical y pronto va, del plano superior, hacia el inferior; después, de éste nuevamente al primero, al dejar un lado la descripción de las gestas reales y mencionar que, sobre el suelo en el que se erige la construcción, hay una alfombra bordada con formas rectangulares; mientras que, por encima de la misma, se halla una paloma de marfil teñido de rojo que sirve de sostén tanto para un escarbunclo, que también brinda claridad a los interiores de la tienda, como para el águila que se encuentra al exterior del pabellón. El binomio águila/paloma es, sin duda, altamente simbólico, pues, al exterior, el águila simboliza el aspecto guerrero, desafiante y defensivo que encarna intradiegéticamente el rey Adrastro; mientras que, al interior, sugiriendo una especie de equilibro, la paloma simboliza a este mismo personaje, en tanto gobernador que brinda serenidad y que, incluso, bajo la perspectiva medieval, alude a Dios. Hasta este punto, las especificaciones del motivo se resumen en el siguiente esquema:

1. Generalidades y materiales de la construcción (11.4217-4222).

1.1. Generalidades (11.4217-4218).

1.2. Material de construcción (11.4219-4221).

1.3. Subexordio de las maravillas (1.4222).

2. Mapamundi (11.4223-4262).

2.1. Introducción al mapamundi (1.4223).

2.2. Disposición física y espacial (11.4224-4226).

2.3. Introducción a las cinco zonas geográficas (11.4227-4228).

2.3.1. Dos zonas frías (11.4229-4232).

2.3.2. Una zona cálida (11.4233-4234).

29 "aquellos [los reyes] que son dignos de memoria". 
2.3.3. Conclusión de las zonas no habitadas (11.4235-4236).

2.3.4. Una zona templada y habitada, generalidades (11.4237-4240).

a) Construcciones arquitectónicas (11.4241-4244).

b) Todalidad de reinos y reyes (11.4245-4246).

c) Los setenta y dos lenguajes (1.4247).

d) Tres mares (11.4248-4250).

f) Los cuatro ríos del Paraíso (1.4251).

g) Los Montes (11.4252-4253).

h) Las Bestias (1.4254).

i) La humanidad (11.4255-4256).

j) El Océano (11.4257-4258).

2.3.5. Conclusión del mapamundi (11.4259-4262).

3. Catálogo de piedras (11.4263-4268).

4. Calendario alegórico (11.4269-4276).

4.1. Disposición espacial (11.4269-4270).

4.2. Estío (11.4271-4273).

4.3. Invierno (11.4274-4276).

5. El mundo histórico y político (11.4277-4284).

5.1. Las leyes de los antepasados (11.4277-4780).

5.2. Las historias de los antepasados (11.4781-4784).

6. Catálogo de animales (11.4285-4286).

7. Elementos de la alfombra (11.4287-4289).

8. Paloma de marfil (11.4290-4296).

9. Tapices del suelo (11.4297-4298).

10. Cuerdas de tensión (11.4299-4301).

11. Dimensiones (11.4302-4306).

Como se observa en el listado anterior, los últimos puntos tratados por el autor son, por una parte, la descripción de las cuerdas —índicas, bermejas y azules- que hacen firme a este edificio e igualmente las califica de preciosas, al ser elaboradas de plata nielada. Éste es, nuevamente, un recurso que se repetirá en las descripciones de tiendas posteriores. Basta pensar, por ejemplo, en la tienda de Alejandro en el Roman d'Alexandre, donde se dice que:

De fin or espanois fuerent fait li paisson, et les cordes de soie, qui tendent environ, et ot aveuc mallé plume d'alerion

$$
(11.1961-1963)^{30}
$$

\footnotetext{
30 "Fueron hechas las estacas de fino oro español y las cuerdas que tensaban los paños de seda tejida eran con plumas de alerión” (11.1961-1963, la traducción es mía).
} 
O bien en la tienda del mismo personaje, pero en el Libro de Alexandre, donde el autor señala que:

Non querría el tiempo en las cuerdas perder, ca avría grant rato en ellas a poner: eran de fina seda; podién mucho valer las lazadas de oro do avién a prender.

Algo parecido se halla, de igual modo, en el Libro de Buen Amor (c. 1268d). Por otro lado, el autor brinda detalles de la cantidad de caballeros — quinientos en totalque pueden circundar la tienda, cuando el monarca duerme o descansa; cómputo que nos habla ya de las grandes dimensiones de esta construcción y cuyo uso evidencia claramente el uso de un tipo de hipérbole específico, la hipérbole por tamaño. Hecho que, de nueva cuenta, se repetirá en la reformulación del motivo. Así, en el Libro de Alexandre se lee que:

Larga era la tienda, redonda e bien tajada:

a dos mil cavalleros darié larga posada.

Apeles el maestro la ovo debuxada:

¡non farié otro omne obra tan esmerada!

(c. 2540)

Sin embargo, como es usual en varias narraciones del Medioevo que tratan de personajes nobles o cortesanos, el exceso no se vincula, en el caso de la tienda de Adrastro, únicamente a las dimensiones de determinado objeto o construcción, sino que también se alude a una abundancia de lujo o costo económico que, en el caso de la descripción de la tienda de este rey, descansa en los materiales básicos de manufactura, seda y oro, además de la mención constante a piedras preciosas. Cabe mencionar que, como en otros casos, estas últimas, como también queda sugerido anteriormente, se presentan en un listado, catálogo o enumeratio que, como todo elemento de este tipo, persigue la finalidad de crear vastedad y aspirar al infinito. Así, como se recordará, acerca del oro que enmarca el mapamundi se menciona:

Emalvaldes, jappes, sardoines, berinz, palmes et cassidoynes, et jagonces et cristolistes, et thompaces et ametistes, a tant en l'or qui l'avironnet, contre soleill grant clarté donent. $(11.4263-4268)^{31}$

\footnotetext{
31 "Había diseminados en el oro tal número de esmeraldas, jaspes, sardónices, berilios, cristales de roca y calcedonias, jancitos y crisólitos, topacios y amatistas, que daba una intensa claridad en el reflejo del sol" (110).
} 
Ya he señalado que, intradiegéticamente, la función de la abundancia de piedras es crear un efecto de luz impresionante en el pabellón del monarca; lo que quizá tendría que añadir aquí es que esta característica puede ser un eco lejano de la descriptio de los palacios del Sol que también brillan con luz impresionante, pues, en las Metamorfosis de Ovidio, se lee que:

Regia Solis erat sublimibus alta columnis, clara micante auro flammasque imitante pyropo, cuius ebur nitidum fastigia summa tegebat, argenti bifores radiabant lumine valvae. materiam superabat opus...

(Metamorfosis, II, 1-5) $)^{32}$

Si esto es válido, el rey Adrasto, en este sentido e intradiegéticamente, encarnaría simbólicamente al astro rey, a cuyo palacio llega un demandante, con el fin de comunicar algo, como si fuese otro Faetón. En el caso del $R T$, este demandante está interpretado por Yocasta y sus hijas, quienes pedirán que cese la guerra entre los hermanos. No obstante, esto no ocurrirá.

Retomando el tema de la enumeratio como estrategia retórica, habría que recordar que ésta no sólo se utiliza al hablar de las piedras preciosas, sino también al momento en que el autor se refiere a los elementos contenidos en el mapamundi como ciudades antiguas, torres y murallas, así como elementos zoológicos que, en esa representación del mundo, también están figurados: "Montres y ot de mil manieres, / oysiaux volanz et bestes fieres" (11.4253-4254). Ésta no es la única mención a elementos animales en la tienda de Adrasto; si se recuerda, la primera parte de la écfrasis de este objeto se inaugura con ciertas generalidades entre las que el autor afirma que la tienda estaba "taillez a bestes et a flors" (1.3178), y aunque nunca devela nombres de flores en específico, sí lo hace con lo que respecta al mundo animal y, al hacerlo, por lo general utiliza, también, un listado.

De esta suerte, además de los animales ya señalados, se entiende que también en la zona habitable del mapamundi están "les bestes de mil maniers, les ostoirs et les

\footnotetext{
${ }^{32}$ En su edición de las Metamorfosis, publicada por Gredos, Fernández Corte propone la siguiente traducción: "El palacio del Sol se alzaba sobre elevadas columnas, resplandeciente de oro brillante y de bronce que imita la llama; blanco marfil cubría sus tejados, las puertas de doble hoja relucían con brillo argénteo. El trabajo era superior al material" (273). Además de las Heroidas, durante la Edad Media y el Renacimiento, las Metamorfosis fue quizá el texto de Ovidio más leído. Con lo que respecta a la primera de esas épocas, los siglos XII y XIII son calificados como una edad ovidiana. Faral señala que: "C'est qu'en effet Ovide était extrêmement familier à tous ceux qui, vers l'époque dont nous parlons [le Moyen Âge central], avaient été formé dans les écoles. Traube [VorlesungenundAbhandlungen]: a dit, en parlant des XIIe et XIIIe siècles: "C'est l'époque qu'on pourrait nommer l'aetasovidiana, qui succède à l'aetasvirgiliana des viIIe et IXe siècles et à l'aetashoratiana des Xe et XIe siècles. En fait, il est curieux de voir comme dans le début du XIIe siècle, le nom d'Ovide se répand dans les catalogues de bibliothèques, comme les copies de ses œuvres se multiplient, comme les poèmes pseudo-ovidiens devinrent nombreux, comme les imitations, les citations, les extraits de ses œuvres attestent et accroissent sa popularité" (Faral, 1913: 4).
} 
espreviers, et les rocins et les destriers" (1.3188-3190), ${ }^{33}$ cita que proviene de la primera parte de la descripción, es decir, en el asedio de Montflor; mientras que, en la segunda, como lo hemos visto, las hazañas de los ascendentes de Adrastro están circundadas con una especie de marco en donde "sont paint liepart, ors et lÿon" (1.4286). Cabe recordar que el autor es claro cuando afirma la ubicación de esos grabados, pues señala que, con respecto a las gestas de los reyes antiguos, los grabados de las bestias se encuentran "En la courtine d'envioron" (1.4285). ${ }^{34} \mathrm{Al}$ observar esto, es evidente que el autor también otorga espacialidad a su descripción mediante frases adverbiales locativas que indican dónde debe el receptor ubicar tal o cual grabado o representación. De esta suerte, el mapamundi se encuentra "un pan devant desus l'entree" (1.4225), ${ }^{35}$ mientras que, entre otras representaciones, los meses del año se ubican "De l'autre part, el destre pan" (1.4269). ${ }^{36} \mathrm{~A}$ propósito de esta característica — que nuevamente es una figura retórica específica, es decir, una dispositio - , cabría resaltar que, con lo que respecta a la representación del mapamundi, la crítica ha vinculado la representación de esta zona con un pasaje ovidiano. En efecto, en sus Recherches sur les sources latines..., Faral propone que, para describir la tienda del rey Adrastro, el autor del Roman de Thèbes no sólo se basó en la descripción de los Palacios del Sol hecha por Ovidio, en las Metamorfosis, sino en el Libro I también de esta obra; concretamente en la primera metamorfosis, en la que se describe el asentamiento del cosmos y lo existente tal como ahora lo conocemos. Los pasajes cotejados por Faral (Recherches sur..., 66) y claramente hermanados son los siguientes:

Par cinc zones la mappe dure, si paintes com les fist Nature. Car les dui qui sont deforeines De glace sont et de noif pleines, et orent ynde la coulour, car auques tornent a froidor; la chaude qui est el mileu, cele est vermeille conme feu: que pour le feu, que por les nois, riens n'i abite en celes trois.

Entre chascune daerrainne et la chaude qui fu maienne, en ot unne qui fu tempree, devers galerne est habitee.

$(11.4227-4240)^{37}$

33 "Las bestias del mil maneras; los azores y los gavilanes, los rocines y los destreros" (89).

34 "Sobre el lienzo circundante" (110).

35 "Sobre la puerta de entrada" (109).

36 "En el lado opuesto, sobre el panel derecho" (110).

37 "El mapa se extendía en cinco zonas, pintadas tal como Naturaleza las había hecho: las de los dos extremos estaban cubiertas de hielo y de nieve, eran de color índico pues tienden a enfriarse. En medio 
Mientras que en la obra de Ovidio se lee lo siguiente:

utque duae dextra caelum totidemque sinistra parte secant zonae, quinta est ardentior illis, sic onus inclusum numero distinxit eodem cura dei, totidemque plagae tellure premuntur. quarumquae media est, non est habitabilis aestu; nix tegit alta duas; totidem inter utramque locavit temperiemque dedit mixta cum frigore flamma

(Metamorfosis, I, VV. 45-50) ${ }^{38}$

En resumen y conclusión, la estructura de la écfrasis de la tienda del rey Adrastro, en el $R T$, resulta compleja, pero analizable en términos de contenido y cómputo. El autor se vale de algunas figuras retóricas, entre las que destacan: la dispositio, la aposiopesis y la enumeratio. La primera de ellas es útil para representar el espacio en el que se encuentra tal o cual elemento descriptivo; la segunda, para hacer una pausa en el discurso y conseguir tensión en la narración; mientras que, la tercera, para crear, intradiegéticamente, una idea de riqueza y nobleza, a la paridad de —extradiegéticamente - aludir a una idea de vastedad e infinito. Esta representación, asimismo, se vale de la representación zoológica para sugerir ciertos elementos simbólicos, entre los que destacan el carácter aguerrido del poseedor del edificio efímero y la naturaleza conciliatoria que puede tener. Finalmente, esta écfrasis es el resultado de la evolución de un motivo: la descripción de un espacio interior de naturaleza real que, si bien bebe de las fuentes clásicas, fue determinante para la reelaboración de las descriptiones de otras tiendas historiadas.

\section{La tienda del rey Adrastro en el Roman de Thèbes}

El texto en francés antiguo lo obtengo de la edición Guy Raynaud de Lage a Le Roman de Thèbes, vv. 3175-3216, 132-135); mientras que, para la traducción, sigo la edición de Paloma Gracia, al El libro de Tebas, publicada por la editorial Gredos (Clásicos medievales, 6, vv. 3175-3216, 89-91):

estaba la zona cálida, roja como el fuego; ya sea por el fuego como por las nieves, nadie habitaba ninguna de esas tres. Entre cada una de las zonas extremas y la cálida — la central— había una templada, habitada hacia el galerno" (109).

38 "Del mismo modo que dos zonas separan el cielo por su parte derecha y otras tantas por la izquierda y la quinta es la más caliente que ellas, así el desvelo del dios dividió el peso encerrado con esta misma proporción y otras tantas regiones quedan impresas en la tierra. De ellas, la que está en el centro no puede ser habitada a consecuencia del calor; abundante nieve cubre dos: igual número colocó entre una y les dio la templanza mezclada con frío" (vv. 45 y ss.). 
Devant la port du donjon tendent au roi son paveillon: touz fu de pailles de coulors, taillez a bestes et a flors.

Bien i sont peintes les estoires, les vielles gestes, les memoires et les justises et les ples, les jugemez et les forfés, et les montaignes et li val et les quaroles et li bal, les puceles et leur ami et les dames et leur mari, les larges prez et les rivieres et les vestes de mil maniers, les ostoirs et les espreviers, et les rocins et les destriers, les vielzhoumes et les chanus et les chauz et les cheveluz, les granz bois et les granz forez, les embuchemenz, les aguez, les cembiaux et les envaïes que danzel Font porlor amis, et les chastiaux et les citez, les fortresces, les fertez.

De trestoutes les creatures sont el tref paintes les natures. Et l'aigle d'or est a neel qui est assis sus le ponmel, c'onques nus hom n'oï parler de tant bel oysel, de tant cler, n'onques nen ot rois Salemons itel aigle en ses paveillons; tant y ot pierres naturaux, tant calcidoines, tant esmax, tanz escharbouclesclerardanz, tantes jagoncesreluisanz, des que soleill et vent la touche, feu ardant giete par la bouche. Envioronot cent tres et plus quisunt a contes et a dus qui leur roi servent par amor et chascun tient de lui s'annor.<smiles>[CH]1C=CC=C1</smiles>

Li trez est merveilleux et granz et entailliez a fleurs par panz. 
ne fu de chanvre ne de lin, ainz fu de pourpure alexandrin. De pourpure fu, ynde et vermeille; dedenz ot paint meinte merveille: a compas i fu mappamonde bien entaille bien roonde; u pan devant desus l'entree, a or batu, menu ouvree.

Par cinc zones la mappe dure, si paintes com les fist Nature. Car les dui qui sont deforeines de glace sont et de noif pleines, et orent ynde la coulour, car auques tornent a froidor; la chaude qui est el mileu, cele est vermeille conme feu: que pour le feu, que por les nois, riens n'i abite en celes trois. Entre chascune daerrainne et la chaude qui fu maienne, en ot unne qui fu tempree, devers galerne est habitee. Iluec sont les citez antives o tours o murset o eschives D'or musique sont li torel, et li portaill et li tournel, tuit li reaume, tuit li roi, et chascune terre par soi, et li septante et dui langaje et mer Betee et mer Sauvage. Rouge merfu fete a neel, et le pas aus filz Ysrael. De Paradis li quatre flun; Ethna y est, qui giete fun. Montres y ot de mil manieres, oysiaux volanz et bestes fieres; et li nostre home i sont bien peint, cil d'Ethÿoppe trestuit teint. Occeanus court par l'ardant, envioron ses rais estendant. Mappamonde fu si grant chose qui l'esgarde pas ne repose, tant voit en mer, tant voit en terre, en grant paine est de tout enquerre. Emalvaldes, jappes, sardoines, berinz, palmes et cassidoynes, et jagonces et cristolistes, et thompaces et ametistes, 
a tant en l'or qui l'avironnet, contre soleill grant clarté donent.

De l'autre part, el destre pan, sont paint li douze mois de l'an.

Estez y est o ses amours, o ses biautez et o ses flours.

O cent coulors est painz Estez; Yver li fet granz tempestez, qui nege et pluet et vente et grelle, et ses ourez ensemble melle. Après i fist paindre li rois et ses justises et ses lois que meintindrent si ancessor qui de Gresce furent seignor. Des rois de Gresce i fist l'estoire, ceus qui sont digne de mémoire, les prouesces et les estours que chascun d'eus fist en ses jors. En la courtine d'envioron sont paint liepart, ors et lÿon. Par terre fu d'un poille brun, ainz n'en veïstes meillor un; entaillez par menu carriax. Colombe ot une en mi le bouge, d'yvoire fu taintice et rouge qui soustint l'aigle et l'escharbocle qui fu Flori le roi, son oncle, que il conquist quant il prist Serse quant il ocist le roi de Persse. Tant com li tres dure desouz de bons tapiz fu jonchiezz touz. Li pesson qui tinnent le tref sont tuit ynde, vermeill et blef; les cordes d'argent neellees, tout environ desouz trecees. Cinc cenz chevaliers touz a armes et mil borjois o granz gisarmes le roi gardent quant il conseill et quant il dort et quant il veille. ${ }^{39}$

${ }^{39}$ Ante la puerta de la torre del homenaje, levantan el pabellón del rey: estaba hecho por entero de sedas multicolores, bordadas con animales y flores. Allí están pintadas las historias, las gestas antiguas, las memorias, los castigos, los procesos, los juicios y los delitos, las montañas y los valles, las danzas y los bailes, las doncellas y sus amigos, las damas y sus maridos, los vastos prados y los ríos, las bestias de mil formas, los azores y los gavilanes, los rocines y los destreros, los ancianos y los canosos, los calvos y los cabelludos, los grandes bosques y las grandes florestas, las emboscadas, los ardides, las justas y las contiendas que los donceles libran por sus amigas, y los castillos y las ciudades y las fortalezas, las plazas fuertes. Las naturalezas de todas las criaturas del mundo estaban pintadas en la tienda. Un águila de oro nielado se erguía en lo más alto: nadie oyó hablar jamás de un ave tan bella, tan resplandeciente, jamás el rey Salomón 


\title{
Obras citadas
}

. S. F. Ilias Latina (Bibliotheca Augustana <https://www.hsaugsburg. de/ harsch/Chronologia/Lspost01/Homerus/hom_ili3.html>). 2002. Le Roman de Thèbes. Ed. Guy Raynaud LaGE. París: Honoré Champion éditeur.

2010. Libro de Alexandre. Ed. Casas Rigall. Madrid: Castalia, 2010. 1997. Libro de Tebas. Trad. Paloma GRACIA. Madrid: Gredos. (Clásicos Medievales, 6)

\author{
ARLIMA. Archives de littérature du Moyen Âge (<http://www.arlima.net/>).
} Beristáin, Helena. 1992. Diccionario de retórica y poética. México: Porrúa. BorgES, Jorge Luis. 1995. Historia de la infamia. Madrid: Alianza.

tuvo águila semejante en sus pabellones. Tenía tantas piedras preciosas - tantas calcedonias, tantos esmaltes, tantos escarbunclos de llameante claridad, tantos jacintos centelleantes- que cuando el sol y el viento la alcanzaban, arrojaba fuego ardiente por el pico. En torno a la tienda había más de cien tiendas de condes y duques que servían lealmente al rey, de quienes todos tenían feudo.

[Más adelante se lee que:]

La tienda era grande y maravillosa, con sus páneles bordados de flores. No era de cáñamo ni de lino, sino de seda alejandrina; de seda índica y bermeja, en cuya superficie se habían pintado numerosas maravillas: un perfecto mapamundi, delicadamente bordado y completamente redondo, se representaba en un panel recubierto de oro y trabajado a maravilla, sobre la puerta de la entrada. El mapa se extendía en cinco zonas, pintadas tal y como Naturaleza las había hecho, pues las de los dos extremos estaban cubiertas de hielo y de nieve, eran de color índico púes tienden a enfriarse. En medio estaba la zona cálida, roja como el fuego, ya sea por el fuego como por las nieves, nadie habitaba ninguna de esas tres. Entre cada una de las zonas extremas y la cálida — que era la central— había una templada, habitada hacia el galerno. Allí estaban las ciudades antiguas con sus torres, sus murallas y sus defensas. Las torretas, los portales y los puentes levadizos eran de paño de oro; todos los reinos, todos los reyes, cada país según su forma y los setenta y dos lenguajes y el mar Blanco y el mar Salvaje. El mar Rojo estaba nielado, como el paso de los hijos de Israel. También estaban los cuatro ríos del Paraíso y el Etna que lanza humo. Había monstruos del mil maneras, pájaros volando y bestias feroces, gruñendo. Los hombres como nosotros estaban bien pintados mientras que los de Etiopia eran completamente negros. El Océano discurría por la zona ardiente, extendiendo sus brazos alrededor. Había diseminados en el oro tal número de esmeraldas, jaspes, sardónices, berilios, cristales de roca y calcedonias, jancitos y crisólitos, topacios y amatistas, que daba una intensa claridad en el reflejo del sol. En el lado opuesto - sobre el panel derecho - estaban pintados los doce meses del año. Allí estaba el Estío con sus amores, sus encantos y sus flores; con cien colores estaba pintado Estío. Invierno provocaba grandes tempestades: nieve, lluvia, viento y granizo, y obligaba a soportar sus huracanes. Después el rey había hecho pintar los juicios y las leyes promulgadas por sus antepasados, que fueron soberanos de Grecia: hizo pintar la historia de los reyes de Grecia dignos de memoria, las proezas, las batallas que realizaron en vida. Sobre el lienzo circundante había pintado leopardos, osos y leones. El suelo estaba cubierto por una alfombra de seda oscura, bordada con pequeñas formas cuadrangulares, con sus pilares y alamenas, ¡jamás visteis otra mejor! En el centro de la cubierta había una paloma de marfil teñido de rojo, que sostenía el águila y el escarbunclo que el rey Flori, tío de Adrastro, ganó cuando conquistó Sersia y mató al rey de Persia. A lo largo de la tienda se extendían por el suelo buenos tapices. Las estacas que sostenían la tienda eran todas índicas, bermejas y azules. Las cuerdas eran de plata nielada, circundaban la parte baja perfectamente tensadas. Quinientos caballeros armados por completo y mil burgueses provistos de alabardas protegían al rey cuando celebraba consejos y cuando dormía y cuando velaba. 
Desprès CAUbriÈre, Catherine. 1996-1997. “La Haine comme résonance du mythe dans Le Roman de Thèbes". Estudios de Lengua y Literatura Francesas, núm. 10-11. Pp. 55-64.

FARAL, Edmond. 1913. Recherches sur les sources latines des contes et romans courtois du Moyen Âge. París: Libraire Ancienne Honoré Champion.

HefFernan, James. 1993. Museum of Words. The Poetics of Ekphrasis from Homer to Ashbery. Chicago: The University of Chicago Press.

JuAn Ruiz, Arcipreste de Hita. 2003. Libro de Buen Amor. Ed. G. B. GyBBon. Madrid: Castalia.

LECOY, Félix. 1974. Recherches sur le Libro de Buen Amor de Juan Ruiz, Arcipreste de Hita. 2a. ed. con supl. de A. D. DEYERMOND. Westmead: Gregg International.

Ovidio. 2003. Metamorfosis. Ed. y trad. Consuelo Álvarez y Rosa Ma. IGLESIAS. Madrid: Cátedra.

Metamorphoseon Libri XV. (Bibliotheca Augustana (<http://www.hsaugsburg.de/ harsch/Chronologia/Lsante01/Ovidius/ovi_me00.html $>$ ).

PinedA, Victoria. 2000. "La invención de la écfrasis". Homenaje a la Profesora Carmen Pérez Romero. Cáceres: Universidad de Extremadura. Pp. 249-260.

SPITZER, Leo. 1955. “The Ode on a Grecian Urn, or Conent vs Metagrmmar". Comparative Literature, 7: 3. Pp. 203-225. 